\title{
The Fante and the Transatlantic Slave Trade.
}

Rochester, University of Rochester Press, 2011, 232 p., bibl., index

\section{Catherine Coquery-Vidrovitch}

\section{(2) OpenEdition}

Journals

Édition électronique

URL : http://journals.openedition.org/etudesafricaines/17874

DOI : $10.4000 /$ etudesafricaines. 17874

ISSN : $1777-5353$

Éditeur

Éditions de l'EHESS

Édition imprimée

Date de publication : 3 octobre 2014

ISSN : 0008-0055

Référence électronique

Catherine Coquery-Vidrovitch, «The Fante and the Transatlantic Slave Trade. », Cahiers d'études africaines [En ligne], 215 | 2014, mis en ligne le 02 octobre 2016, consulté le 24 septembre 2020. URL http://journals.openedition.org/etudesafricaines/17874 ; DOl : https://doi.org/10.4000/ etudesafricaines. 17874

Ce document a été généré automatiquement le 24 septembre 2020

(c) Cahiers d'Études africaines 


\title{
The Fante and the Transatlantic Slave Trade.
}

Rochester, University of Rochester Press, 2011, 232 p., bibl., index

\author{
Catherine Coquery-Vidrovitch
}

\section{SHUMWAY, Rebecca. - The Fante and the Transatlantic Slave Trade. Rochester, University of Rochester Press, 2011 , 232 p., bibl., index}

1 L'ouvrage traite du rôle joué par les notables fanti de la côte de l'or dans l'explosion du commerce atlantique des esclaves, dont un million aurait quitté les côtes ghanéennes au cours du XVIII siècle. Du côté occidental, Brésiliens, Anglais et Français, Danois et Néerlandais devinrent à partir $\mathrm{du} \mathrm{XVII}^{\mathrm{e}}$ siècle les principaux partenaires, tout en se livrant une concurrence acharnée, dont témoigne la quantité des forts qui se succédaient tous les quatre à cinq kilomètres, servant surtout d'entrepôts pour stocker l'or et les esclaves qui attendaient les navires venus de l'ensemble des ports de l'Europe atlantique. L'étude se concentre sur un fort important mais jusqu'à présent non étudié, celui d'Anomabo, qui aurait à lui seul concentré la moitié des départs d'esclaves. L'objet est aussi de montrer comment, de par leur rôle essentiel de go-between, la période de la traite a engendré des mutations culturelles profondes des populations fanti de la région.

Celles-ci ont répondu aux injonctions de l'époque en exploitant les opportunités économiques ainsi offertes. L'ampleur nouvelle du commerce transforma leurs structures politiques, et créa les conditions d'une nouvelle identité culturelle. Il s'agissait auparavant de petites chefferies indépendantes les unes des autres organisées sur des principes lignagers. Mais, surtout à partir des années 1730, une élite militarisée entreprit de réguler le commerce. Ses membres trouvèrent la cohésion nécessaire pour répondre aux exigences croissantes du commerce maritime, tout en restant suffisamment flexibles pour s'adapter à toutes les situations. Cette expérience de 
coopération poursuivie sur plusieurs générations pour préserver leurs intérêts communs et leur souveraineté les conduisit à transformer ce chapelet de chefferies, jusqu'alors souvent en guerres picrocholines les unes contre les autres entre populations parlant au moins trois langues principales (le guan, l'etsi et l'akan), en un ensemble solidaire, qui devint connu au xviII ${ }^{\mathrm{e}}$ siècle sous le nom de culture (et de langue) fanti. Entendons-nous bien, et l'ouvrage le précise clairement: il s'agissait d'une alliance de puissants, prêts à tout pour protéger leurs intérêts réciproques qui ne furent pas minces, puisqu'on estime à un million le nombre d'esclaves qui transitèrent par la côte ghanéenne au XVIII ${ }^{\mathrm{e}}$ siècle pour être déportés en Amérique. C'est donc une catégorie privilégiée, mais très minoritaire de notables qui tirèrent avantage du contexte international, en constituant des sortes de guildes de marchands sans pour autant susciter, à la différence de nombre d'autres formations, l'émergence d'un État centralisé. Dans un contexte où les risques de brigandage, de rapts et de mise en esclavage étaient quasi permanents, c'est à cette époque qu'ils mirent au point des groupes locaux de milice armée, dites compagnies asafo, susceptibles d'être parfois mobilisés en masse par la coalition fanti dans son ensemble, notamment contre les invasions des Achanti. Cela leur donna la force de résister à cette menace : les Achanti tentèrent plusieurs expéditions de conquête du pays sans réussir à leur ravir durablement l'accès direct à la traite européenne. Ces Asafo - qui ont été déjà étudiés sous une forme anthropologique mais sans les mettre en relation avec l'histoire de l'esclavage - ont contribué à transformer la vie sociale des communautés, en créant des liens d'échange, de voisinage et de solidarité qui n'étaient plus limités aux liens familiaux des lignages. Il est remarquable de constater à quel point ces solidarités asafo sont restées vivaces dans la vie culturelle fanti contemporaine, sous la forme d'associations de chant et de danse, de parades à drapeaux, etc.

3 Les chefs fanti, jusqu'au xIX ${ }^{e}$ siècle, ne furent pas soumis aux Européens, mais bien les " maîtres de la côte », comme le reconnaît en 1753 Thomas Melvil, " gouverneur » de Cape Coast Castle ${ }^{43}$. Ils ont pris sous leur protection les métis côtiers qui, de leur côté, avaient profité de l'affaiblissement, voire de la disparition progressive de l'hégémonie portugaise sur la côte ouest-africaine.

4 Cette étude est très sérieusement documentée. Dotée d'une bibliographie d'une vingtaine de pages, d'un index et de nombreuses références, c'est un outil précieux d'histoire à la fois politique et culturelle mettant l'accent sur l'émergence, le rôle actif et le dynamisme évolutif du groupe fanti sous l'impact du siècle le plus dur de son histoire.

\section{NOTES}

43. Melville, 24 avril 1753, cité pp. 1-157. 